\title{
Socioeconomic Disparities in Healthcare Utilization Under Universal Health Coverage: Evidence From Dubai Household Health Survey
}

\section{Shreena Malaviya}

Johns Hopkins Bloomberg School of Public Health, Johns Hopkins University

David Bishai ( $\sim$ dbishai@jhsph.edu )

Johns Hopkins Bloomberg School of Public Health, Johns Hopkins University

Meenu Mahak Soni

Dubai Health Insurance Corporation, Dubai Health Authority

El Daw Suliman

Dubai Health Insurance Corporation, Dubai Health Authority

\section{Research Article}

Keywords: System of Health Accounts, UHC, healthcare utilization, socioeconomic equity

Posted Date: February 21st, 2022

DOI: https://doi.org/10.21203/rs.3.rs-1369899/v1

License: (c) (i) This work is licensed under a Creative Commons Attribution 4.0 International License.

Read Full License 


\section{Abstract \\ Background}

In 2013, Dubai implemented the Insurance System of Advancing Health in Dubai (ISAHD) law which required mandatory health insurance for all residents of Dubai effective in 2016. This study compares the effect of the ISAHD on the utilization and out-of-pocket (OOP) expenditures for low and high socioeconomic status sub-groups.

\section{Methods}

The study used the 2014 and 2018 Dubai Household Health Survey (DHHS) a representative survey of Dubai stratified as: 1) Nationals; 2) Non-nationals in households; 3) Non-nationals in collective housing; and 4) Non-nationals in labor camps. The probability that each household would have expenditures was calculated, then multiplied by a weighted estimate of the average total OOP expenditure.

\section{Results}

Overall Dubai's health spending rose from 12.8 billion AED (3.4 billion US \$) in 2014 to 16.8 billion AED (4.6 billion US \$) in 2017. Concurrently, the OOP share in total health spending in Dubai fell from $25 \%$ in 2014 to $13 \%$ in 2017 . From 2014 to 2018 , there were increases in the utilization of inpatient, outpatient and discretionary services for all groups except non-nationals living in camps. In 2018, nationals spent a total of 1,064.65 AED, non-nationals in households spent 675.01 AED, collective households spent 82.35 AED, and labor camps spent 100.32 AED out-of-pocket per capita for healthcare expenditures. During and after the implementation of ISAHD, there was a substantial growth in the OOP expenditure per capita for nationals and non-nationals in households due to increased utilization. OOP spending did not rise for the lower-income non-National households.

\section{Conclusion}

Dubai has been successful in reducing the household share of OOP expenditures by shifting the financial burden to government and employers. Emiratis and expatriate households increased their health service utilization after ISAHD but blue-collar workers did not. Remaining non-financial barriers to care for Dubai's blue-collar workers must be identified and addressed.

\section{Key Messages}

- Mandatory Universal Health Insurance in Dubai was started in 2013 and has reduced out of pocket health spending but by 2018 it did not increase health utilization in lower socio-economic status migrant groups 
- Between 2014 and 2018 overall spending per capita and the utilization of outpatient and inpatient health services increased

- Inpatient health utilization doubled and out of pocket spending increased five fold in $\mathrm{n}$ Emirati nationals

- Inpatient health utilization did not increase and out of pocket spending increased by $8 \%$ in NonNationals living in Collective Housing

\section{Background}

Universal Health Coverage (UHC) aims to reduce financial burdens and impoverishment due to health expenditures while increasing access to important health services for all people (1). The path to UHC requires universal enrollment in a system for financial protection as well universal access to appropriate promotive, preventive, curative, and rehabilitative health services of high-quality. Universal health coverage can prevent health-related financial shocks that can push households into poverty $(1,2)$.

The emirate of Dubai, one of the seven emirates of the United Arab Emirates, has advanced significantly on their path to achieving UHC. The health sector of the Emirate of Dubai accounted for $4.6 \%$ of the GDP in 2018. The sector along with its free zones, excluding Dubai Health Care City Authority (DHCA), is regulated and overseen by the Dubai Health Authority (DHA), a public organization involved in strategic oversight of the sector and enhancing private sector engagement. DHA carries out regulation, licensing, and management of public and private facilities as well as the financing of the public facilities. The Ministry of Health and Prevention (MOHAP) and Dubai Health Care City Authority (DHCA) also play a role in oversight over a limited number of facilities compared to the DHA.

The population of Dubai was an estimated 4.67 million in 2018, of whom 1.47 million were holders of a Dubai visa but who lived in other emirates. Geographically, the inhabitant population of Dubai consists of $8 \%$ UAE nationals and $92 \%$ expatriates. There are nearly 16 million tourists that visit Dubai each year based on data from 2018. Approximately $60 \%$ of the population consists of low-income blue-collar workers. Blue collar expatriate workers have shorter stays than white collar expatriates and they immigrate during high demand in the construction and infrastructure sectors, and emigrate when the projects are completed.

Before the healthcare financing reforms in 2013, the citizens of UAE (Emiratis) residing in Dubai could receive free healthcare from government providers. They also received publicly provided health insurance that largely covered privately provided services. Prior to the reforms nearly all non-Emiratis residents in Dubai would be charged for healthcare services except for emergency, maternal and child care (3). The expatriates could either pay out-of-pocket for healthcare or be covered through individually or employer purchased health insurance plans. They also had the option to purchase a health coverage plan from the federal level of UAE, that entitled beneficiaries to access medical services at all Ministry of Health facilities for minimal fees (3). Thus, there were marked differences in the coverage and access to 
healthcare between different population sub-groups primarily determined by their citizenship status and income levels $(4,5)$.

To counter the growing inequality in access and affordability of healthcare, Dubai reformed its health system with policies designed to achieve Universal Health Coverage (UHC). In November 2013, the government of Dubai passed the Mandatory Health Insurance law - Law 11, known as the Insurance System of Advancing Health in Dubai (ISAHD), requiring mandatory health insurance enrollment for all residents of Dubai effective in 2016. The law was implemented in stages across Dubai to reduce disruptions to the healthcare system. The period before 2013 can be considered the pre-ISAHD phase, 2013-2015 would be the implementation phase of ISAHD, and 2016 onwards is the post- implementation phase of ISAHD.

ISAHD placed a mandate requiring health insurance on all employers and employees. It was a requirement for all work visas issued by Dubai government. This model ensured that Dubai's residents had financial access to healthcare and protects the financing system from adverse risk selection, where people who think they are at low-risk could opt out of buying insurance. The private insurance contracts offer patients the choice to seek treatment with government or private health care providers. In addition, the government of Dubai provides health insurance for all its expatriate employees and their families (Husband/wife and up to 3 children under the age of 21 years) through the ENAYA Program, and for all the citizens of Dubai through the SAADA program. One measure of the success of the ISAHD law could be defined by the decrease in the out-of-pocket expenditure (OOP) by the population. Another measure of success would be an increase in the utilization of health services. A third measure of success would be comparative parity in health care utilization trends across social groups, noting that there might be agebased differences in needs when comparing Emirati Nationals to expatriate blue collar and white-collar workers.

\section{Methods}

\section{Population Selected for Analysis}

The population of health system users of Dubai can be classified as follows:

1. UAE Nationals (Emiratis) in the Emirate of Dubai

2. Non-nationals (Expatriates) with employment visas from Dubai and residence inside Dubai

3. Non-nationals (Expatriates)with employment visas from Dubai and residence outside Dubai

4. Tourists who visit Dubai

The Dubai Statistics Centre considers only the first two groups as part of Dubai's population. However, according to the law, government agencies and private employers in Dubai are mandated to offer healthcare coverage to all employees with Dubai employment visas regardless of their geographical 
residence. Thus, for the purposes of this study, the first three groups will be considered. We can further segregate the non-nationals based on their type of residence - households, collective housing and labor camps. Non-nationals residing in labor camps represent a less privileged social class than those living in households and those living in collective housing have intermediate social status. Health spending by tourists is not included in this study as the population of short-term tourists varies seasonally.

\section{Data - Dubai Household Health Survey (DHHS) 2014 and 2018}

The Dubai Household Health Survey (DHHS) is the largest comprehensive household survey of healthcare and health issues carried out in the Emirate of Dubai. The survey provides a statistically accurate and representative outlook of key health and healthcare variables across the entire population of Dubai. It was first conducted in 2009, and repeated in 2014 and 2018.

The surveys of 2014 and 2018 were based on a multi-stage stratified cluster sample. The sampling was designed so that after weighting it would be representative of the four sub-populations: UAE citizens, Nonnationals living in households, Non-nationals living in collective housing, and Non-nationals living in labor camps. Surveyors personally visited these randomly selected households to obtain detailed information on issues ranging from household health expenditure, and access to health services to questions on exercise levels, dietary habits, lifestyle diseases, mental health, and a detailed module on the use of public and private health services in Dubai. The 2018 survey was designed by DHA and the logistics and field work was led by the Dubai Statistics Center (DSC), and had a response rate of $96 \%$. The design and methodology of the survey were adopted from those used in the World Bank's Living Standards Measurement Surveys (LSMS), the World Health Organization's World Health Surveys (WHS) and the US Center for Disease Control's National Health Interview and Examination Surveys (NHIES).

Importance weights were assigned by Dubai Statistics Center because UAE citizens were oversampled. After weighting, the sample was representative of a geographical population of 3.2 million Dubai residents as of 2018. The sample size for 2018 was a total of 9,630 persons in 2200 housing units of whom 5,665 were UAE citizens, 2,342 were Non-Citizens in Households, 1,335 were Non-Citizens in collective housing, and 288 were Non-Citizens in labor camps. The samples in 2014 and 2018 included a total of 3271 and 2200 separate household units respectively. The survey was sanctioned by the institutional review board of the Dubai Health Authority.

The surveyors each received extensive training in the collection of self-reported expenditure data and interviewed a person in the household who is 15 years and above and most knowledgeable about recent medical utilization. After collecting a household roster and basic demographics for each household member, the surveyor asked whether each household member had had any outpatient utilization in the last 30 days, made any discretionary purchases of medical supplies or over the counter medicines (mentioning blood pressure cuffs, blood sugar monitors, orthopedic supplies, medicines, etc.) in the last 30 days and whether each household member had had an overnight inpatient stay in the last 12 months. For households where more than one member had experienced outpatient utilization in the last 30 days, an individual member was selected at random and details of their medical events were collected to 
investigate the total of out of pocket spending for various categories of discretionary spending, outpatient spending and inpatient spending, after adjusting for the appropriate weights. All household members who had overnight inpatient stay in the last 12 months were asked to fill an inpatient module questionnaire.

\section{Data - System of Health Accounts 2012-2017}

The results from the published System of Health Accounts (SHA) from 2012-2017 were used for triangulation to ensure the OOP expenditure estimates from the survey data were accurately captured for the population defined (6).

\section{Analysis}

In our analysis of DHHS we calculated the probability that each of the 4 categories of household would have any discretionary, or any outpatient, or any inpatient out of pocket spending. For outpatient spending the household survey included the number of outpatient encounters experienced in a 30-day period and the number of hospital admissions experienced in a 12-month period. Then for each type of household the probability of any spending was multiplied by a weighted estimate of the annual average total out of pocket expenditure for households who incurred that type of event. Estimates were adjusted for the incidence of multiple outpatient visits in a month. Only 5 households reported greater than one hospitalization per month, so this adjustment had a negligible effect on estimates of hospitalization incidence and costs. Health care spending data can be dominated by outliers that could dramatically skew estimates of average expected spending in small samples. This was found to be true of the DHHS health spending data. Consequently, all calculations of average health spending excluded outliers above the 99th percentile to reduce the skewness of the data.

Estimates of outpatient and discretionary spending in the last 30 days were annualized to offer estimates of total annual out of pocket spending for each of the four types of households. Finally, total annual spending for each type of household in 2018 was multiplied by estimates of the proportion of these households in the population of Dubai in 2014 based on government data showing that at this time there were $8 \%$ UAE citizens, $42 \%$ UAE non-nationals living in households, $11 \%$ UAE non-nationals living in collective housing, and $39 \%$ living in labor camps.

The findings on out of pocket spending for both 2014 and 2018 were used to linearly interpolate to 2015, 2016 and 2017 by adjusting for population growth of the total population and assuming that the proportion of each type of household remained constant. Costs from different years were deflated from and inflated, using the consumer price index so that costs are expressed in real AED with a baseline of 2014.

\section{Results}

We can observe the impact of the ISAHD implementation on the household expenditure and healthcare utilization between the population sub-groups as viewed through the System of Health Accounts in Fig. 1. 
Overall, there has been a significant decrease in the total household OOP expenditure for the entire population after the implementation of ISAHD [6, Fig. 1].

Table 1 shows the changes in health utilization between 2014 and 2018 for the four demographic groups in the study. Utilization probabilities are typically higher for Emirati nationals. It is important to remember that Emirati nationals include a significantly higher proportion of seniors than non-Emirati households. There were increases in utilization of services for almost all groups for all types of health care utilization. Notable exceptions were the lack of any increase in inpatient utilization for Non-Emiratis living in collective housing.

Table 1

Probability of Healthcare Utilization in 2014 and 2018

\begin{tabular}{|c|c|c|c|c|}
\hline Group & Year & $\begin{array}{l}\text { Any Discretionary } \\
\text { Utilization }\end{array}$ & $\begin{array}{l}\text { Any Outpatient } \\
\text { Utilization in Month }\end{array}$ & $\begin{array}{l}\text { Any Inpatient Utilization in } \\
12 \text { Months }\end{array}$ \\
\hline \multirow{2}{*}{$\begin{array}{l}\text { Emirati } \\
\text { Nationals }\end{array}$} & 2014 & $0.8 \%$ & $10.7 \%$ & $3.6 \%$ \\
\hline & 2018 & $2.2 \%$ & $18.3 \%$ & $6.9 \%$ \\
\hline \multicolumn{5}{|c|}{ Non-Emiratis living in } \\
\hline \multirow[t]{2}{*}{ Households } & 2014 & $0.6 \%$ & $7.4 \%$ & $2.3 \%$ \\
\hline & 2018 & $3.3 \%$ & $14.8 \%$ & $4.1 \%$ \\
\hline \multirow{2}{*}{$\begin{array}{l}\text { Collective } \\
\text { Housing }\end{array}$} & 2014 & $0.2 \%$ & $2.4 \%$ & $0.7 \%$ \\
\hline & 2018 & $0.3 \%$ & $4.3 \%$ & $0.7 \%$ \\
\hline \multirow{2}{*}{$\begin{array}{l}\text { Labor } \\
\text { Camps }\end{array}$} & 2014 & $0.1 \%$ & $4.6 \%$ & $1.0 \%$ \\
\hline & 2018 & $0.0 \%$ & $14.6 \%$ & $3.1 \%$ \\
\hline
\end{tabular}

Table 2 estimates the total annual spending showing that in 2014, the total OOP expenditure per capita for nationals (AED 182.83) and non-nationals living in households (AED 219.15) was significantly higher than that of the other two groups. Given their higher incomes, the share of the total OOP as part of their income was lower.

Following full implementation of the health insurance reforms, in 2018, nationals spent a total of 518 million AED, non-nationals in households spent 1,496 million AED, collective households spent 63 million AED, and labor camps spent 118 million AED out-of-pocket for healthcare expenditures. We observe a substantial increase in the OOP expenditures with the highest growth in the Emirati nationals (482\% growth from 183 to 1065 AED) and the lowest growth in the group of non-nationals living in collective households ( $8 \%$ growth from 76 to 82 AED). Assuming income has remained relatively stable since 2014, the share of the total OOP as part of their income substantially increased for all groups with the exception 
of collective households (+ $1 \%$ growth). There was an increase by $30 \%$ in OOP as share of income for those in labour camps. [Table 2, Fig. 2]

Table 2

OOP per capita (AED) for Different Healthcare Services

\begin{tabular}{|c|c|c|c|c|c|c|}
\hline Year & $\begin{array}{l}\text { Population } \\
\text { Sub-Group }\end{array}$ & $\begin{array}{l}\text { Total OOP } \\
\text { Discretionary } \\
\text { Spending per } \\
\text { capita }\end{array}$ & $\begin{array}{l}\text { Total OOP } \\
\text { Outpatient } \\
\text { Spending per } \\
\text { capita }\end{array}$ & $\begin{array}{l}\text { Total OOP } \\
\text { Inpatient } \\
\text { Spending per } \\
\text { capita }\end{array}$ & $\begin{array}{l}\text { Total } \\
\text { OOP } \\
\text { Spending } \\
\text { per capita }\end{array}$ & $\begin{array}{l}\text { Total } \\
\text { OOP as } \\
\text { Share of } \\
\text { Income }\end{array}$ \\
\hline \multirow[t]{4}{*}{2014} & Nationals & 46 & 134 & 3 & 183 & $0.03 \%$ \\
\hline & $\begin{array}{l}\text { Non- } \\
\text { Nationals in } \\
\text { Households }\end{array}$ & 42 & 171 & 7 & $0.07 \%$ & \\
\hline & $\begin{array}{l}\text { Non- } \\
\text { Nationals in } \\
\text { Collective } \\
\text { Housing }\end{array}$ & 60 & 0 & 76 & $0.08 \%$ & \\
\hline & $\begin{array}{l}\text { Non- } \\
\text { Nationals in } \\
\text { Labor } \\
\text { Camps }\end{array}$ & 1 & 39 & 0 & $0.18 \%$ & \\
\hline \multirow[t]{4}{*}{2018} & Nationals & 461 & 484 & 119 & 1,065 & $0.18 \%$ \\
\hline & $\begin{array}{l}\text { Non- } \\
\text { Nationals in } \\
\text { Households }\end{array}$ & 281 & 348 & 47 & $0.21 \%$ & \\
\hline & $\begin{array}{l}\text { Non- } \\
\text { Nationals in } \\
\text { Collective } \\
\text { Housing }\end{array}$ & 3 & 79 & 0 & 82 & $0.09 \%$ \\
\hline & $\begin{array}{l}\text { Non- } \\
\text { Nationals in } \\
\text { Labor } \\
\text { Camps }\end{array}$ & 0 & 82 & 19 & 100 & $0.44 \%$ \\
\hline
\end{tabular}

Over the course of implementation of ISAHD, we observed a substantial growth in aggregated total OOP expenditure for nationals and non-nationals in households. However, the growth for the other two demographic groups was attenuated in comparison [Table 3, Fig. 3]. We also observed that the growth of OOP expenditure per capita was significantly higher for the Nationals than the Non-Nationals. As seen before, growth for the lower-income households was negligible [Figure 4]. 
Table 3

Total OOP Expenditure (Million AED) from 2014-2018

\begin{tabular}{|llllll|}
\hline Population & $\mathbf{2 0 1 4}$ & $\mathbf{2 0 1 5}$ & $\mathbf{2 0 1 6}$ & $\mathbf{2 0 1 7}$ & $\mathbf{2 0 1 8}$ \\
\hline Nationals & $55 \mathrm{M}$ & $56 \mathrm{M}$ & $412 \mathrm{M}$ & $508 \mathrm{M}$ & $518 \mathrm{M}$ \\
\hline Non-Nationals in Households & $336 \mathrm{M}$ & $343 \mathrm{M}$ & $1190 \mathrm{M}$ & $1466 \mathrm{M}$ & $1496 \mathrm{M}$ \\
\hline Non-Nationals in Collective Housing & $31 \mathrm{M}$ & $32 \mathrm{M}$ & $51 \mathrm{M}$ & $62 \mathrm{M}$ & $64 \mathrm{M}$ \\
\hline Non-Nationals in Labor Camps & $56 \mathrm{M}$ & $57 \mathrm{M}$ & $94 \mathrm{M}$ & $116 \mathrm{M}$ & $118 \mathrm{M}$ \\
\hline
\end{tabular}

After the implementation of the ISAHD, the utilization and expenditure patterns for different healthcare services varied between the population sub-groups. Previously, all groups spent more on outpatient care than inpatient and discretionary. By 2018, Nationals and non-nationals were spending more on discretionary and outpatient services than inpatient services. However, non-nationals in collective households had increased the proportion of their expenditure on outpatient services and decreased the proportion of expenditure on discretionary services. The group living in labour camps had increased their proportion of their OOP spending on inpatient services [Table 4]. 
Table 4

Comparison of health service OOP spending and its proportional makeup - 2014 vs 2018

\begin{tabular}{|clllll|}
\hline Year & $\begin{array}{l}\text { Population sub- } \\
\text { group }\end{array}$ & $\begin{array}{l}\text { Total OOP } \\
\text { Expenditure per capita } \\
\text { (AED) }\end{array}$ & $\begin{array}{l}\text { Share of } \\
\text { Discretionary } \\
\text { Expenditure }\end{array}$ & $\begin{array}{l}\text { Share of } \\
\text { Outpatient } \\
\text { Expenditure }\end{array}$ & $\begin{array}{l}\text { Share of } \\
\text { Inpatient }\end{array}$ \\
\hline 2014 & 183 & $23 \%$ & $69 \%$ & $2 \%$ \\
\hline & Expenditure \\
\hline $\begin{array}{l}\text { Nationals } \\
\begin{array}{l}\text { Non-Nationals in } \\
\text { Households }\end{array}\end{array}$ & 219 & $18 \%$ & $73 \%$ & $3 \%$ \\
\hline $\begin{array}{l}\text { Non-Nationals in } \\
\text { Collective Housing }\end{array}$ & 76 & $19 \%$ & $75 \%$ & $0 \%$ \\
\hline $\begin{array}{l}\text { Non-Nationals in } \\
\text { Labor Camps }\end{array}$ & 40 & $2 \%$ & $91 \%$ & $0 \%$ \\
\hline $\begin{array}{l}\text { Nationals } \\
\begin{array}{l}\text { Non-Nationals in } \\
\text { Households }\end{array}\end{array}$ & 1,065 & $40 \%$ & $43 \%$ & $10 \%$ \\
\hline $\begin{array}{l}\text { Non-Nationals in } \\
\text { Collective Housing }\end{array}$ & 82 & $39 \%$ & $48 \%$ & $6 \%$ \\
$\begin{array}{l}\text { Non-Nationals in } \\
\text { Labor Camps }\end{array}$ & 100 & $4 \%$ & $89 \%$ & $0 \%$ \\
\hline
\end{tabular}

\section{Limitations}

There are a few limitations associated with this analysis. Firstly, the data collected through the DHHS is self-reported and does not allow for the collection of OOP expenditure estimates for non-traditional medicines. The DHHS oversampled Emirati Nationals and used sample weights to ensure better precision for estimates from this population. Health spending estimates are sensitive to outliers with extreme values of utilization and spending. To limit this distortion our analysis censored observations of expenditure above the $99 \%$ ile.

In addition, there are possible cultural and language barriers that prevent accurate collection of data from blue-collar workers. The reports in the DHHS were validated against electronic claims processed by the Dubai Health Authority and published in the official System of Health Accounts.

\section{Conclusions}

The main goal of ISAHD was to ensure that every resident of Dubai would have access to affordable health care and prevent catastrophic health expenditure. In addition, ISAHD was implemented with a goal of leading health improvement for all the residents, especially for low-income residents. By 2016, all of the residents were covered under government or private insurance. Compared to 2014 when household OOP expenditure accounted for $25 \%$ of healthcare spending, Dubai has been successful in reducing the 
out of pocket share to $12 \%$ by 2018 which is comparable with most OECD countries. By comparing the 2018 estimates to previous SHA studies $(6,7,8)$, we can see that the burden of healthcare costs has shifted more from households to government and employers.

As a proportion, most of the out of pocket health care spending was on outpatient care and discretionary care. For Emiratis and expatriate households, the utilization of health services increased after ISAHD and remained relatively stable afterwards. The increase in utilization is primarily attributed to the purchase of medical goods as a result of the higher insurance coverage. The presence of insurance lowered the effective out of pocket prices for medical goods and simultaneously increased utilization as well as total out of pocket spending.

The insurance-induced changes for Emiratis and expatriate white collar households, in medical utilization post-implementation of ISAHD corroborates the experimental results of the RAND experiment and the results of the Oregon Health Insurance experiment conducted in the US that showed how more insurance coverage stimulates more utilization $(9,10)$.

The response to improved health insurance financial coverage for non-nationals in collective households and labor camps is strikingly different from the more well-off groups in the population. Collective households and people in expatriates in labor camps did not increase their per capita use of health services. We confirmed internal reports validating increased coverage of new blue-collar workers enrolled in coverage based on the number of new insurance contracts. So, there is evidence that the mandated coverage required by the ISAHD was enforced. For some other reason these groups did not show the typical increase in utilization after receiving health insurance.

Dubai has one of the highest rates of population migration largely due to blue-collar workers (11) who have relatively lower incomes and are less socially connected to resources required to address health needs $(12,13)$. Migrant populations are often selectively healthier than the populations they emerge from (14). However, migrants' diminished social position in their host country can produce challenges in health care seeking, making them more likely to use urgent and emergency services and less likely to use outpatient specialty care (15). Similar to other countries, many blue-collar migrant workers in the MiddleEast have limited access to health resources (12-15). Studies of Middle-Eastern immigrants have found that migrant workers from poorer groups are at a high risk of mental illness and occupational injuries due to their living and working conditions (16-22). Occupational injuries are especially high for migrant construction workers $(18,19)$. They are also at high risk for family separation, acculturative stress and discrimination that can negatively impact their physical, emotional, and social health (13).

With the implementation of ISAHD and the focus on employer health insurance, it was expected that the reform would remove the financial barriers to healthcare experienced by blue-collar workers and thereby increase their access and utilization of health services. However, our study did not find a dramatic increase in health care utilization. One unlikely possibility, is that due to a healthy migrant effect and their relative youth the expatriate blue collar workers simply did not need much health care services to begin with and so having better insurance did not induce an increase in utilization. Another possibility is that 
workers' individual barriers apart from financial cost that prevents them from seeking healthcare. These include obstacles in scheduling, transport, and logistics, cultural and language barriers, health literacy, and coverage awareness (23-29). Given these factors, it is possible that workers are not aware they have treatable conditions, and/or are hesitant to seek care because they do not understand the resources and health coverage available to them (23-29). They may also perceive low job security and worry that they will be sent back to their country if their employer suspects they have an illness (30). The results of this study are consistent with the literature that documents lower utilization of healthcare services by migrant workers, but the data cannot confirm whether the reason is better health or worse non-financial obstacles to utilization or both.

If the intent of ISAHD was to extend a safety net of effective health care coverage to all residents and thereby to improve their health outcomes, then understanding the remaining barriers to care for Dubai's blue-collar workers should become a priority (31). Future healthcare reforms should focus on mitigating the barriers faced by workers in accessing health care. Reforms should focus on understanding patterns of utilization in migrant workers that have recently arrived by comparing them to migrants who have been in the country for a longer period (27). Interventions could include government and employer organized programs in cultural competency for providers and outreach in multiple languages to raise health literacy, increase awareness of health coverage, and increase logistical access to healthcare providers $(32,33)$.

\section{Abbreviations}

AED - United Arab Emirates Dirham

DHA - Dubai Health Authority

DHCA - Dubai Health Care City Authority

DHHS - Dubai Household Health Survey

DSC - Dubai Statistics Center

ISAHD - Insurance System of Advancing Health in Dubai

MOHAP - Ministry of Health and Prevention

OOP - Out-of-pocket

SHA - System of Health Accounts

UAE - United Arab Emirates

UHC - Universal Health Coverage

\section{Declarations}


Ethics approval and consent to participate: Not applicable because the ethics committee in Dubai ruled that no formal ethics approval was required for the secondary data analysis of the non-identifiable data used in this study. The Dubai Household Health Surveys conducted by the Dubai Statistics Center complied with the national guidelines of UAE. These surveys are similar to the Dubai Household Surveys and World Household Surveys. The consent of the respondent is attached in the survey questionnaire and no data is collected without the consent of the respondent.

Consent for publication: Not applicable

Availability of data and materials: The datasets used and analyzed during the current study were received from the Dubai Statistics Center.They are available from the corresponding author on reasonable request.

Competing interests: Dr. Meenu Mahak Soni and Dr. El Daw Suliman are currently employed with the Dubai Health Authority, Dubai, United Arab Emirates.

Funding: There are no financial conflicts of interest to disclose.

Authors' contributions: Shreena Malaviya, Dr. David Bishai, Dr. Meenu Sodhi, and Dr. El Daw Suliman have significantly contributed to the design of the study; acquisition, analysis and interpretation of the data; and written the manuscript. All authors have approved the submitted version and have agreed both to be personally accountable for their own contributions and ensure that questions related to the accuracy or integrity of any part of the work, even ones in which the author was not personally involved, are appropriately investigated, resolved, and the resolution documented in the literature.

Acknowledgements: The authors thank the Dubai Health Authority and the Dubai Health Insurance Corporation for their support during the study.

\section{References}

1. World Health Organization. Making fair choices on the path to universal health coverage: Final report of the WHO Consultative Group on Equity and Universal Health Coverage.

2. Knaul FM, González-Pier E, Gómez-Dantés O, García-Junco D, Arreola-Ornelas H, Barraza-Lloréns M, Sandoval R, Caballero F, Hernández-Avila M, Juan M, Kershenobich D. The quest for universal health coverage: achieving social protection for all in Mexico. The Lancet. 2012 Oct 6;380(9849):1259-79.

3. World Health Organization. Regional Health Systems Observatory-EMRO. World Health Organization. 2011 Apr.

4. Koornneef E, Robben P, Blair I. Progress and outcomes of health systems reform in the United Arab Emirates: a systematic review. BMC health services research. 2017 Dec;17(1):1-3.

5. Khoja T, Rawaf S, Qidwai W, Rawaf D, Nanji K, Hamad A. Health care in Gulf Cooperation Council countries: a review of challenges and opportunities. Cureus. 2017 Aug;9(8). 
6. Dubai Health Insurance Corporation. Health Accounts System of Dubai 2016-2017. Government of Dubai. 2019.

7. Hamidi S. Evidence from the national health account: the case of Dubai. Risk management and healthcare policy. 2014;7:163.

8. Dubai Health Insurance Corporation. Health Accounts System of Dubai 2013-2014. Government of Dubai. 2016

9. Newhouse JP. Free for all?: lessons from the RAND health insurance experiment. Harvard University Press; 1993.

10. Finkelstein A, Taubman S, Wright B, Bernstein M, Gruber J, Newhouse JP, Allen H, Baicker K, Oregon Health Study Group. The Oregon health insurance experiment: evidence from the first year. The Quarterly journal of economics. 2012 Aug 1;127(3):1057 - 106.

11. Baldwin-Edwards M. Migration in the Middle East and the Mediterranean. Geneva: Global Commission on International Migration; 2005 Sep.

12. World Health Organization. The world health report 2003: shaping the future. World Health Organization; 2003.

13. Flynn MA, Wickramage K. Leveraging the domain of work to improve migrant health. International Journal of Environmental Research and Public Health. 2017 Oct;14(10):1248.

14. Jass G, Massey DS. Immigrant health: Selectivity and acculturation. IFS Working Papers; 2004.

15. Graetz V, Rechel B, Groot W, Norredam M, Pavlova M. Utilization of health care services by migrants in Europe-a systematic literature review. British medical bulletin. 2017 Jan 20;121(1):5-18.

16. Adhikary P, Keen S, Van Teijlingen E. Health Issues among Nepalese migrant workers in the Middle East. Health Science Journal. 2011;5(3):169-75.

17. Joshi S, Simkhada P, Prescott GJ. Health problems of Nepalese migrants working in three Gulf countries. BMC International Health and human rights. 2011 Dec 1;11(1):3.

18. Al-Arrayed A, Hamza A. Occupational injuries in Bahrain. Occupational Medicine. 1995 Oct 1;45(5):231-3.

19. Ghaemi H. Building towers, cheating workers: Exploitation of migrant construction workers in the United Arab Emirates. Human Rights Watch; 2006.

20. Naithani D, Jha A. Challenges faced by expatriate workers in the Gulf Cooperation Council countries. Naithani, P. and Jha, AN (2010). Challenges faced by expatriate workers in the GCC countries. International Journal of Business and Management. 2009 Nov 1;5(1):98-104.

21. Al-Maskari F, Shah SM, Al-Sharhan R, Al-Haj E, Al-Kaabi K, Khonji D, Schneider JD, Nagelkerke NJ, Bernsen RM. Prevalence of depression and suicidal behaviors among male migrant workers in United Arab Emirates. Journal of immigrant and minority health. 2011 Dec 1;13(6):1027.

22. Suphanchaimat R, Pudpong N, Tangcharoensathien V. Extreme exploitation in Southeast Asia waters: Challenges in progressing towards universal health coverage for migrant workers. PLoS medicine. 2017 Nov 22;14(11):e1002441. 
23. McGeehan N, Keane D. Enforcing migrant workers' rights in the United Arab Emirates. International Journal on Minority and Group Rights. 2008 Jan 1;15(1):81-115.

24. Rust G, Fryer Jr GE, Phillips Jr RL, Daniels E, Strothers H, Satcher D. Modifiable determinants of healthcare utilization within the African-American population. Journal of the National Medical Association. 2004 Sep;96(9):1169.

25. Hnilicová H, Dobiášová K. Migrants' health and access to health care in the Czech Republic. Cent Eur J Public Health. 2011 Sep 1;19(3):134-8.

26. Davidovitch N, Filc D, Novack L, Balicer RD. Immigrating to a universal health care system: utilization of hospital services by immigrants in Israel. Health \& place. 2013 Mar 1;20:13 - 8.

27. Dias SF, Severo M, Barros H. Determinants of health care utilization by immigrants in Portugal. BMC health services research. 2008 Dec 1;8(1):207.

28. McMichael C, Healy J. Health equity and migrants in the Greater Mekong Subregion. Global health action. 2017 Jan 1;10(1):1271594.

29. Loganathan T, Rui D, Ng CW, Pocock NS. Breaking down the barriers: Understanding migrant workers' access to healthcare in Malaysia. PloS one. 2019 Jul 3;14(7):e0218669.

30. Koser K. The impact of financial crises on international migration: Lessons learned. IOM, International Organization for Migration; 2009.

31. Onwujekwe O, Onoka C, Uzochukwu B, Hanson K. Constraints to universal coverage: inequities in health service use and expenditures for different health conditions and providers. International journal for equity in health. 2011 Dec 1;10(1):50.

32. Osei Asibey B, Agyemang S. Analysing the influence of health insurance status on peoples' health seeking behaviour in rural Ghana. Journal of tropical medicine. 2017 May 8;2017.

33. Hoerster KD, Mayer JA, Gabbard S, Kronick RG, Roesch SC, Malcarne VL, Zuniga ML. Impact of individual-, environmental-, and policy-level factors on health care utilization among US farmworkers. American journal of public health. 2011 Apr;101(4):685-92.

34. Asbu EZ, Masri MD, Kaissi A. Health status and health systems financing in the MENA region: roadmap to universal health coverage. Global health research and policy. 2017 Dec 1;2(1):25.

35. Latif Alnasir FA. Health of Migrant Workers; A Matter Of Concern. Middle East Journal of Family Medicine. 2015 Mar 1;13(2).

36. Hassan HA, Houdmont J. Health and safety implications of recruitment payments in migrant construction workers. Occupational medicine. 2014 Jul 1;64(5):331-6.

\section{Figures}




\section{Trends in Health Financing Sources}

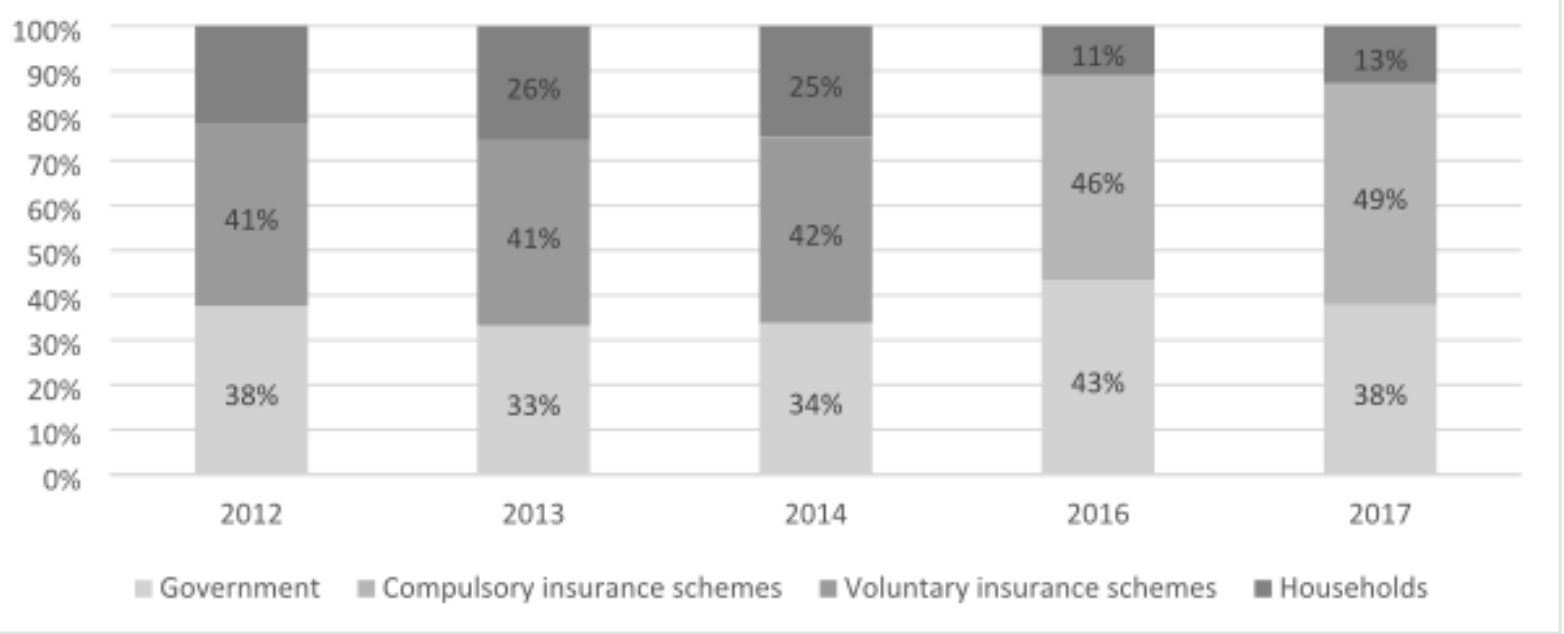

\section{Figure 1}

Trends in Health Financing Schemes, Dubai (2012-2017)

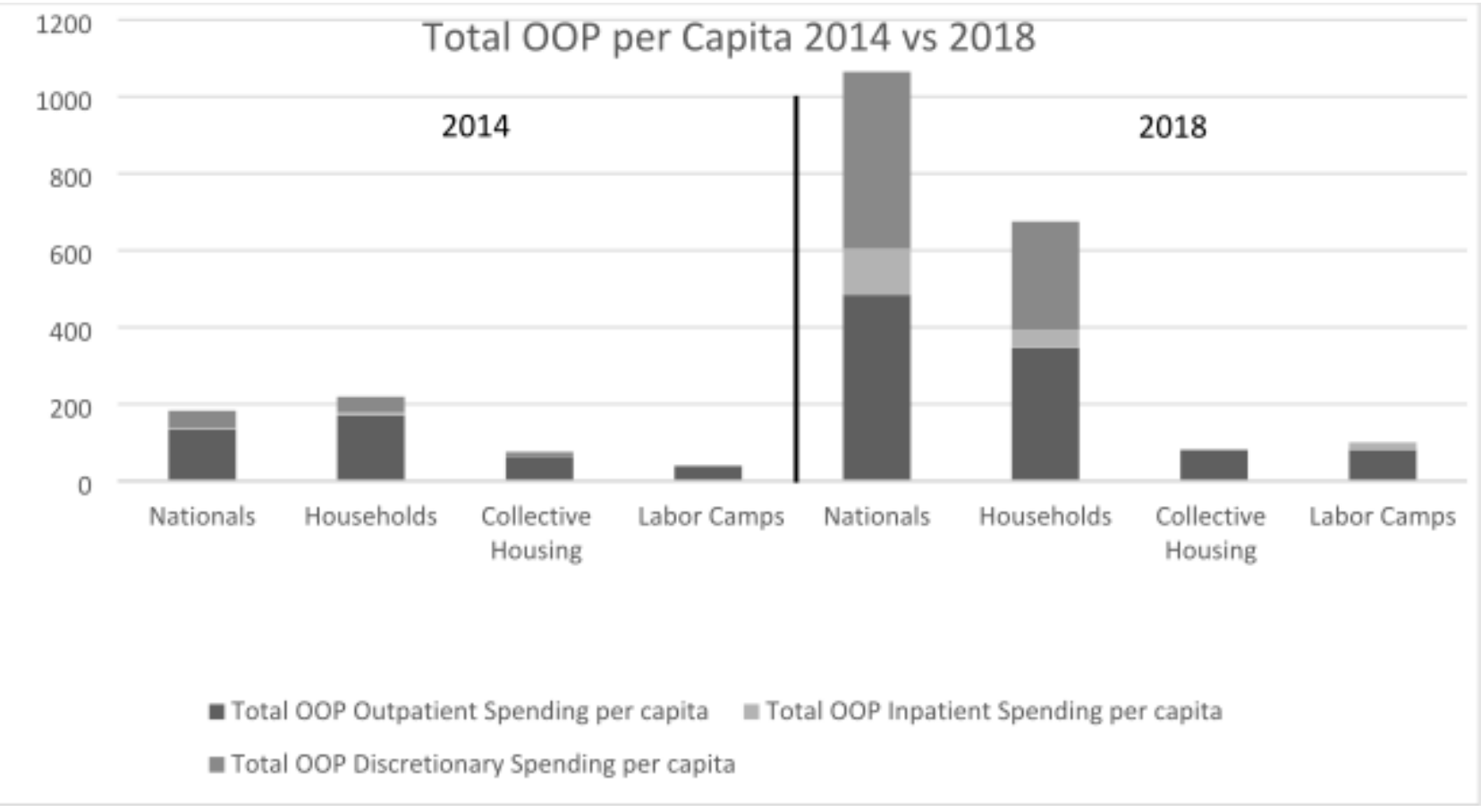

Figure 2

Total OOP per capita (AED) comparison for each population group - 2014 vs 2018 
OOP Expenditure Trend for Each Population Group

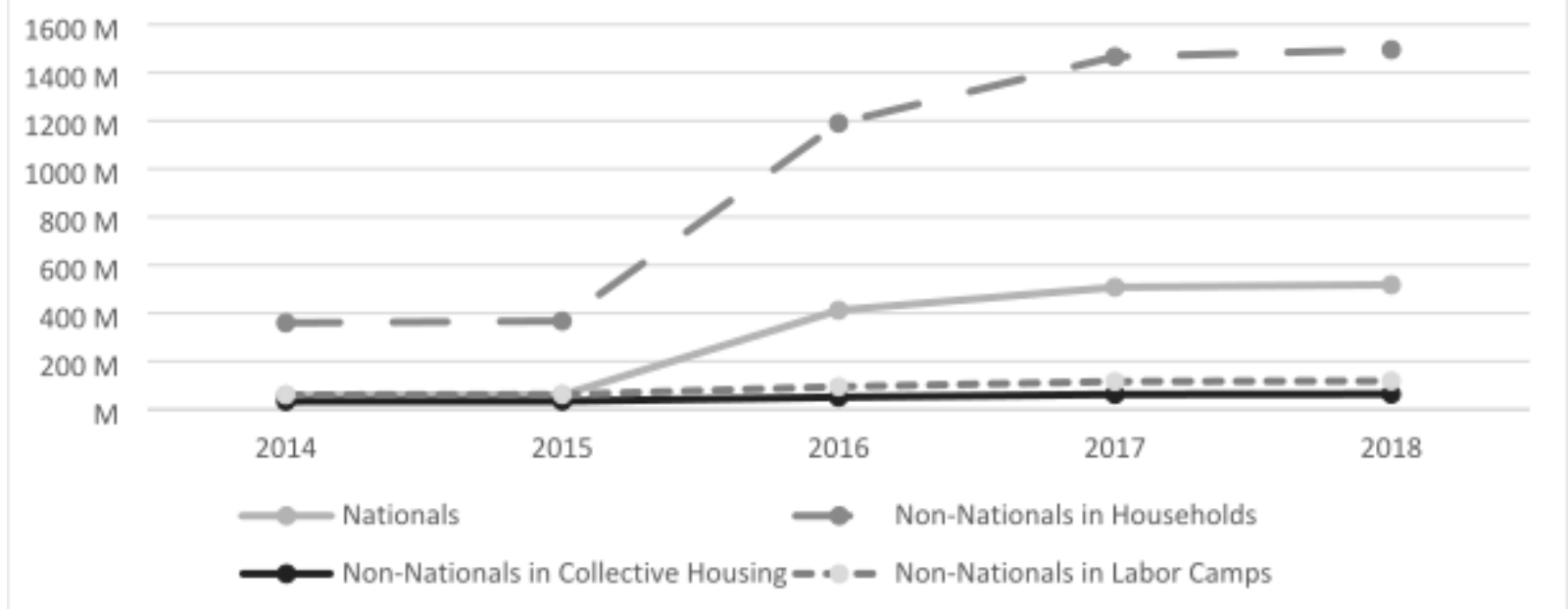

\section{Figure 3}

Total OOP Expenditure (Million AED) Trend for Each Population Group

OOP Expenditure per capita Trend for Each Population Group

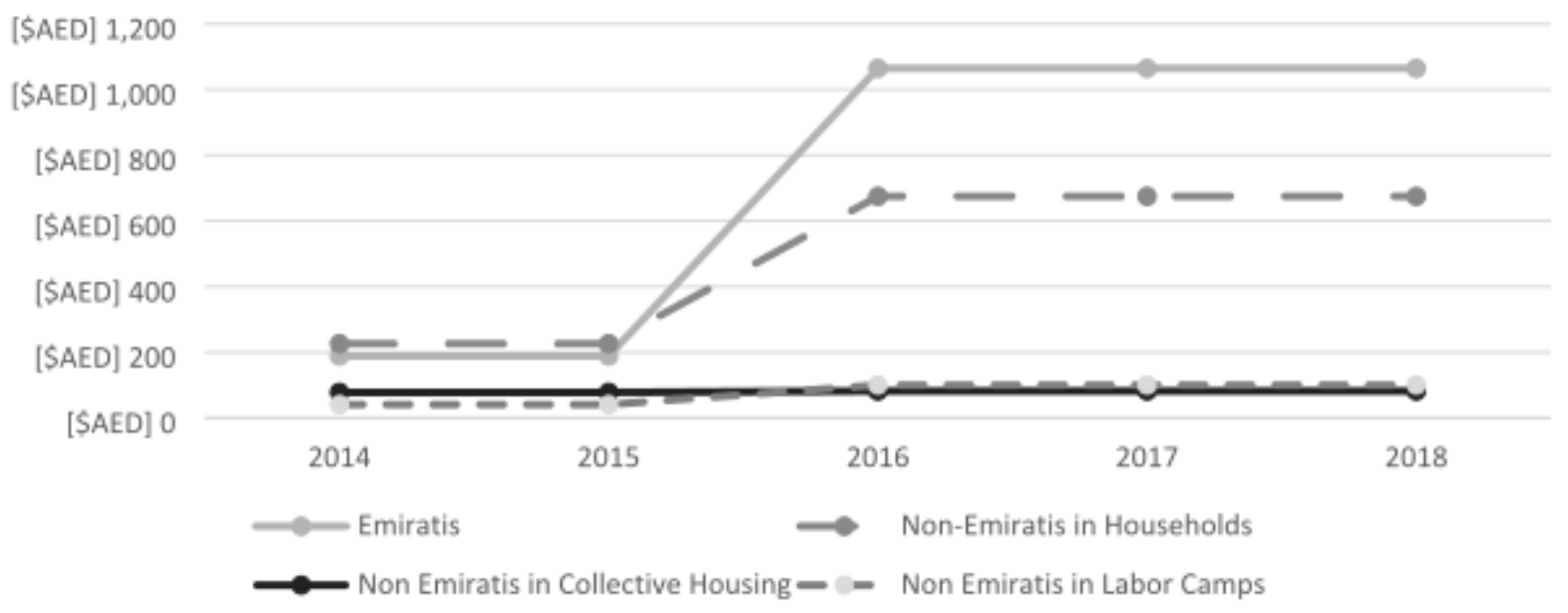

\section{Figure 4}

OOP Expenditure per capita Trend for Each Population Group 